\title{
Long-term follow up Results of Ongley method Prolotherapy Combining Lumbar Manipulation, targeted Spinal Injections, and Mckenzie-type Rehabilitation Exercises for the Management of Arthropathic low back pain: A Case Report with 9-year follow up
}

\author{
Inklebarger J* \\ Department of Orthopedics, the London College of Osteopathic Medicine, UK
}

Submission: November 28, 2017; Published: December 18, 2017

*Corresponding author: Inklebarger J, Department of Orthopedics, the London College of Osteopathic Medicine, NW 6QH, London, UK, Email: james.inklebarger@yahoo.co.uk

\begin{abstract}
Introduction: Prolotherapy, also known as Sclerotherapy, 'Bongling' or Regenerative injections, commonly utilizes substances such as dextrose, dextrose-glycerol-phenol (Ongley's Solution or P2G), and sodium morrhuate. Targeted injections of these solutions into the tendon enthesis, facet joints space, and lumbosacral ligaments, aims to stimulate natural healing processes through inflammation, and thereby optimizes lumbar motor unit stability, which in turn may relieve pain. Accurate lumbar ligament injection delivery requires practical knowledge of anatomical landmarks, but may also be performed under ultrasound or fluoroscopic guidance. This case report with 9-year post spinal prolotherapy follow up, reviews a patient with lumbar facet joint arthrosis, who had suffered from long-term constant and chronic low back pain, progressively worsening sleep disturbance and loss of ADL function. Over Prior pain relieving strategies including relative rest, analgesics \& anti-inflammatory medications, physiotherapy, and corticosteroid iliolumbar and facet joint injections had failed. She received day before corticosteroid-anesthetic injections in the points outlined below, followed by lumbar spine manipulation and a series 8 of lumbar prolotherapy injections combined with Mckenzie-type rehabilitation exercises. She was pain free on follow up 6 weeks following the last injection with reported restoration of full function. On 9-year follow up, her lower back had remained essentially pain free with continued enjoyment of full ADL activities and functional abilities.
\end{abstract}

Conclusion: An Ongley's approach combining day-before spinal corticosteroid injections, pre-prolotherapy spinal manipulations, followed by 8 prolotherapy injections in combination with Mckenzie-type exercises, may be an effective long-term management of chronic arthrogenic low back pain

Keywords: Prolotherapy; Sclerotherapy; Ongley's solution; Lumbar; Sacroiliac joints; Mckenzie; Manipulation

\section{Introduction}

Prolotherapy (Proliferative Therapy) injections induce a controlled inflammatory response, stimulating the natural healing responses of injured or lax ligaments, other connective tissue elements, and degenerative conditions of the musculoskeletal system. Also referred to as Bongling, sclerotherapy, regenerative injection therapy, and nonsurgical ligament reconstruction, these solutions are injected into lax or weakened spinal ligaments and adjacent lumbosacral soft tissue structures, relieving back pain, by restoring normal motor unit stability.
This case follows a 59-year-old housewife who reported chronic, constant worsening long-standing low back pain, sleep disturbance, stiffness, and intermittent severe flares interfering with her ability to carry out normal ADL tasks. She had not responded to relative rest and physiotherapy, and derived only short-term respite with analgesics \& anti-inflammatory medications, and spinal corticosteroid-anesthetic injections. Following day before spinal corticosteroid injections, and pretreatment initial lumbo-pelvic manipulations, she commenced a series of 8 lumbar spinal prolotherapy injection sessions 
with Ongley's solution (P2G) injections, in conjunction with Mackenzie exercises. On follow-up 6 weeks after the final injections, she reported that her lower back felt more stable and had become pain free. Upon telephone and face to face follow up discussion with her son 9 years later, it was reported that her low back had remained completely pain free for the entire period and she continued to engage in full domestic chores and ADL activities without limitation.

\section{Case Report}

This report follows a 59-year-old female housewife who had presented with a history of chronic low-standing centralized lower lumbar segment non-radicular low back pain gradually worsening over time with sleep disturbance. The pain was described as dull, constant, and aching with progressive worsening over time. Over the past several months she had begun to suffer chronic unremitting pain, restricted range of moment and difficulties with ADL walking and standing for 1015 minutes. She also complained of sleep disturbance, night waking, pain flares when turning in bed and difficulties finding a position of ease. She also reported generalized low back stiffness, which was worse towards the end of the day and also worsened by cold weather. Ibuprofen and Tylex, spinal manipulation, and activity modifications partially and temporarily relieved her symptoms. She was however, unresponsive to physiotherapy and recommended core strengthening exercises. Prior to commencing prolotherapy, she had received bilateral L4/5 and L5/S1 facet joint injections kenalog (triamcinolone acetonide) $10 \mathrm{mg}$ in $1 \mathrm{ml}$ lidocaine for each joint circa 6 weeks apart. These injections also afforded partial abatement of pain for 2-3 weeks, but unfortunately the pain returned to pre injection levels. She was otherwise fit and well, without recollected incidence of significant injuries or fractures. There was no history of diabetes, cardio-pulmonary, gastrointestinal, or genitourinary disease. $\mathrm{X}$-rays of the lumbar spine reported mild bilateral lower lumbar segment facet-joint arthropathy with disc spaces well preserved. She reported no other joint pains and inflammatory blood tests were also unremarkable.

Initial examination was limited due to pain and guarding. She was of normal weight and there was no limb atrophy. She had difficulty disrobing and requires assistance to remove her shoes and socks and displayed an antalgic gait with a slight limp and off-loading of the right lower limb. She also had difficulty transferring. Her posture was hypolordotic. Pain and guarding limited exam and there was global restriction of all lumbar ranges of motion. She was able to partially squat, and displayed satisfactory power on repeat unilateral heel raises but required balance support for these maneuvers. She had maintained a slightly forward stooped gait posture with short stride.

Slump tests were deferred due to pain. Her leg length was equal. Lower limb sensation was intact and the deep tendon reflexes were brisk and equal bilaterally. Hip and knee range of motion were symmetrical and essentially pain free. Full power was noted on testing of the extensor hallicis longus, peroneals, and foot dorsiflexor muscles. The dorsal pedal pulses were palpable and toe capillary refill was less than 2 seconds. Passive straight leg raise reproduced centralized and bilateral paraspinal discomfort at around 70 degrees bilaterally. Bilateral supine hip compression with the knee at 90 degrees also reproduced right greater than left upper sacroiliac joint pain. There was no palpable pubic symphysis or greater tronchanteric tenderness noted. The abdomen was also soft and non-tender. Lumbar springing and palpation reproduced local pain in the bilateral right greater than left iliolumbar ligaments. Intersegmental palpation between the L3-4, L4-5, and L5-S1 vertebral levels reproduced exquisite centralized pain. These same levels were also reported painful on right greater than left rotational provocation.

Hip extension was full and the femoral stretch test negative. There were no gross signs of hypermobility. On six week follow up she reported that her lower back was now pain free. The reported chronic low grade back ache, stiffness and intermittent flares had completely abated and she was able to sleep through the night. She had ceased all pain medications, and had resumed all of her ADL's and full domestic work activities. On review she was able to walk, stand and transfer without difficulty, and demonstrated full, unrestricted and pain free lumbar spine range of motion. There was however some residual discomfort on bilateral right greater than left iliolumbar ligament prodding, but the remainder of the exam was unremarkable and no further pain was reproduced with any of the above-mentioned provocative tests.

\section{Method}

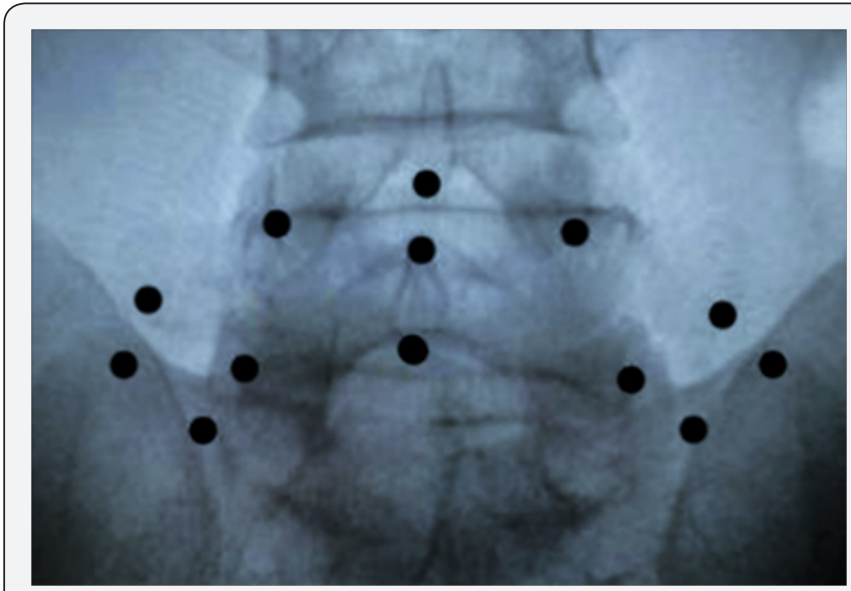

Figure 1: Black dots represent the solution (initial kenalog \& then prolotherapy) injection points.

The patient was consented regarding the potential complications of spinal prolotherapy [1]. Initially she was injected with a solution of $80 \mathrm{mg}$ of kenalog in $20 \mathrm{ml}$ of $1 \%$ lidocaine (Figure 1). Her lumbar spine and sacroiliac joints were then manipulated using side posture short lever technique. 
The following day she received the first of a series of 8 lumbar prolotherapy spinal at one to two week intervals with followup planned 6 weeks after the last injection. She kept all her scheduled appointments and all injection procedures were carried out without incident. She was also advised to perform daily Mckenzie exercises both during and after the period of prolotherapy treatment [2].

During the prolotherapy procedure, each of the below diagramed sites were then injected with 1-2 ml of a hyperosmolar solution of $\mathrm{P} 2 \mathrm{G}$, comprised of dextrose $25 \%$, glycerol $25 \%$ and phenol $2 \%$, mixed with $1 \%$ lidocaine in equal parts $(50 / 50)$ to a total volume of $20 \mathrm{ml}$ [3]. The injections targeting each of the anatomical landmarks locations outlined in Figure 1, which included the bilateral posterior sacroiliac ligaments, iliolumbar ligaments, lower 2 segment facet joint capsules, tips of the transverse processes, and the supraspinous and interspinous ligaments.

\section{Conclusion}

Prolotherapy in conjunction with pre-treatment corticosteroid lidocaine injection they day before, and manipulation followed by an Mckenzie-based exercise program (Ongley method) may be an effective and safe means for the long-term management of chronic arthropathic low back pain [4]. The day before corticosteroid injections may help to break the pain cycle and control the initial inflammatory reaction anticipated by the $\mathrm{P} 2 \mathrm{G}$ solution. Initial pre-injection manipulation(s) may aid in normalizing spinal alignment. Under the principle of specific adaptation to imposed demands, rehabilitation exercises performed both between and after completion of prolotherapy sessions, are likely integral to re-establishing functional and organized spinal ligamentous stability and integrity. Prior studies have noted limited efficacy of prolotherapy as a stand-alone treatment, while others have been critical of a combined methods approach of using manipulation and exercise adjunctively with prolotherapy. However, later Cochrane reviews seem to have supported the utility of Ongley's method [5]. Though combined modalities may create challenges to future clinical trial design, this approach may nonetheless be vital of optimal pain management and functional restoration.

\section{Acknowlegement}

Special thanks to Dr. Milne Ongley for ongoing guidance and advice and thanks to Dr. Simon Petrides for providing the fluoroscopic template image. I'd like to also thank Mr. Ken Faulkner for editing.

\section{References}

1. Rabago D, Slattengren A, Zgierska A, (2010) Prolotherapy in Primary Care Practice, Prim Care 37(1): 65-80.

2. McKenzie R, May S (2003) The Lumbar Spine: Mechanical Diagnosis and Therapy, 2 vols. Waikanae, Spinal Publications, New Zealand.

3. Banks A (1991) A rationale for prolotherapy. Journal of Orthopedic Medicine 13: 54-59.

4. Ongley MJ, Klein RG, Dorman TA, Eek BC, Hubert LJ (1987) A new approach to the treatment of chronic low back pain. Lancet 2(8551): 143-146.

5. Dagenais S, Yelland MJ, Del Mar C, Schoene ML (2007) Prolotherapy injections for chronic low-back pain, Cochrane Database Syst Rev 2: CD0040593.

\section{Your next submission with Juniper Publishers} will reach you the below assets

- Quality Editorial service

- Swift Peer Review

- Reprints availability

- E-prints Service

- Manuscript Podcast for convenient understanding

- Global attainment for your research

- Manuscript accessibility in different formats

( Pdf, E-pub, Full Text, Audio)

- Unceasing customer service

Track the below URL for one-step submission https://juniperpublishers.com/online-submission.php 